\title{
How Do I Manage Hypertension in Patients with Advanced Chronic Kidney Disease Not on Dialysis? Perspectives from Clinical Practice
}

This article was published in the following Dove Press journal: Vascular Health and Risk Management

\author{
Erietta Polychronopoulou' \\ Gregoire Wuerzner (D) ${ }^{1,2}$ \\ Michel Burnier ${ }^{1,2}$ \\ 'Service of Nephrology and \\ Hypertension, University Hospital, \\ Lausanne, Switzerland; ${ }^{2}$ Hypertension \\ Research Foundation, Saint-Légier, \\ Switzerland
}

\begin{abstract}
In the general population, the prevalence of moderate and severe chronic kidney disease (CKD) is usually below $5 \%$ but this figure is often higher in specific groups of patients such as those with type 2 diabetes. Patients with advanced CKD (CKD stage 3b and 4) are at high or very high cardiovascular risk, and their risk of progressing towards endstage kidney disease (CKD stage 5) and the need of renal replacement therapy are elevated. Hypertension is a major cause of poor cardiovascular and renal outcomes in severe CKD. Therefore, an adequate control of blood pressure (BP) is mandatory. However, normalizing BP is often challenging in these patients because the clinical management of hypertension in advanced CKD is not well defined and rarely supported by large randomized controlled trials. In the present review, we discuss the characteristics of hypertension in advanced CKD, excluding dialysis, and its management integrating data from recent clinical studies and a pragmatic approach enriched by a long-standing clinical experience.
\end{abstract}

Keywords: hypertension, chronic kidney disease, CKD stage 3b-4, blockers of the reninangiotensin, diuretics, calcium antagonists, SGLT2 inhibitors

\section{Introduction}

Chronic kidney disease (CKD) is defined as abnormalities of kidney structure or function present for $>3$ months leading to a sustained reduction in glomerular filtration rate (GFR) and/or to the occurrence of kidney damage markers, such as albuminuria. ${ }^{1,2}$ Today, CKD is classified in five stages according to the level of GFR (G1 to G5) and three categories according to the absence or presence of albuminuria (A1, A2 and A3). Worldwide, the prevalence of CKD ranges between $7 \%$ and $15 \%{ }^{3,4}$ The high and rising prevalence of subjects with CKD stages 1 to $3 \mathrm{a}$ and a mild to moderate reduction in estimated GFR (eg above $45 \mathrm{~mL} / \mathrm{min} / 1.73 \mathrm{~m}^{2}$ ), is due in part to the ageing population but also to the growing prevalence of diabetes and hypertension. ${ }^{3,5}$ Fortunately, the prevalence of moderate to severe (stage 3b) and advanced (stage 4) CKD with estimated GFR below $30 \mathrm{~mL} / \mathrm{min} /$ $1.73 \mathrm{~m}^{2}$ is lower, usually below $5 \%$, but with large variations depending on countries $^{6}$ and populations studied. In the US population, the percentage of NHANES 2013-2016 participants with CKD stages $3 \mathrm{~b}$ and 4 was $2.1 \%{ }^{7}$ In the Swiss population, ${ }^{8} 1.6 \%$ of the 1353 participants randomly enrolled in the Swiss Survey on Salt had CKD stages $3 \mathrm{~b}$ and 4 . However, in a similar survey among Swiss patients with type 2 diabetes followed by general practitioners, the
Correspondence: Michel Burnier Service of Nephrology and Hypertension University Hospital, Rue du Bugnon 17, Lausanne I0II, Switzerland

Email michel.burnier@chuv.ch
Vascular Health and Risk Management 202I:17 I-II

(c) (i) (8) ๑ 2021 Polychronopoulou et al. This work is published and licensed by Dove Medical Press Limited. The full terms of this license are available at https://www.dovepress. (c) accessing the work you herbby accept the Terms. Non-commercial uses of the work are permitted without any further permission from Dove Medical Press Limited, provided the work is properly attributed. For permission for commercial use of this work, please see paragraphs 4.2 and 5 of our Terms (https://www.doveppess.com/terms.php). 
prevalence of stages $3 \mathrm{~b}$ and 4 CKD was $8.5 \% .^{9}$ In a UK primary care cohort of patients older than 60 years and enriched with CKD patients, $23 \%$ of patients pertained to the stages $3 \mathrm{~b}$ and 4 groups. ${ }^{10}$

Patients with advanced CKD not on dialysis are at high or very high cardiovascular risk according to hypertension guidelines. ${ }^{11}$ Indeed, the risk of myocardial infarction, heart failure, stroke or peripheral artery disease is significantly higher in patients with CKD than in the non-CKD population and, as expected, the cardiovascular risk rises further as kidney function declines. ${ }^{1,5,11,12}$ Hence, patients with advanced CKD have a greater risk to die from any cardiovascular event than to progress towards end-stage kidney disease (ESKD). ${ }^{13}$ In this respect, analyses made by the Chronic Kidney Disease Prognosis Consortium have demonstrated that both estimated GFR and the urinary albumin/creatinine ratio (ACR) are independent prognostic factors for mortality in the general population: ${ }^{14}$ the lower the GFR and the higher the ACR, the greater the hazard ratio for all-cause and cardiovascular mortality. ${ }^{14}$

In the context of kidney diseases, hypertension plays a special role, as it may be a cause as well as a consequence. Among the main clinical complications associated with the progression of kidney diseases such as anemia, metabolic acidosis, metabolic bonne disease, hypertension is the most prevalent. Indeed, in CKD stage 2, about one third of patients are hypertensive and when GFR is below $60 \mathrm{~mL} / \mathrm{min} / 1.73 \mathrm{~m}^{2}$, the prevalence of hypertension is up to $>80 \%$ and reaches almost $100 \%$ in advanced CKD (stage 4 and 5 not on dialysis). ${ }^{15}$ Hypertension is an important determinant of CKD progression and a major risk factor for cardiovascular events. Therefore, lowering blood pressure (BP) to recommended targets represents a major task in the management of patients with $\mathrm{CKD},{ }^{16}$ the two primary objectives being: 1) to prevent the occurrence of cardiovascular events and the associated mortality and 2) to protect against the progression of CKD towards ESKD needing dialysis or transplantation.

\section{Blood Pressure Profile and Targets in Advanced CKD}

Two important patterns characterized the hypertensive phenotype in people with advanced CKD. The first is the high prevalence of nocturnal hypertension ${ }^{17}$ and uncontrolled masked hypertension due mainly to elevated BP values at night. ${ }^{18,19}$ The second is the high proportion of patients with apparent or truly resistant hypertension. ${ }^{20}$ The elevated nighttime BP in patients with advanced CKD can be explained in several ways including an increased prevalence of sleep apnea syndrome due to sodium and water retention, ${ }^{21,22}$ an increased sympathetic nerve activity and a reduced capacity to excrete sodium during daytime as GFR declines. ${ }^{23}$ Indeed, a high nocturnal BP enables to maintain the $24 \mathrm{~h}$ sodium balance when kidney function is impaired. In this respect, Fukuda et al have nicely shown that as GFR declines sodium excretion, albuminuria and BP increase during the night. ${ }^{24}$ Regarding resistant hypertension, several studies have demonstrated a high prevalence in patients with advanced CKD. In a recent review written by Georgianos and Agarwal, the prevalence of resistant hypertension in treated hypertensive patients with CKD ranged between $28.1 \%$ and $40.4 \%{ }^{20}$ Both nocturnal and resistant hypertension are associated with an increased risk of cardiovascular events. $^{18,19}$

The practical implication of these two observations is that out-of-office BP measurements providing both daytime and nighttime BP values should be performed more regularly in patients with hypertension and CKD. Ambulatory blood pressure monitoring should be used not only to confirm the eventual diagnosis of resistant hypertension but also to ascertain that, under treatment, $\mathrm{BP}$ control is achieved around the clock. ${ }^{25}$ In this respect, as recommended by guidelines, only validated devices should be used.

Besides these two patterns of hypertension, one should mention that systolic hypertension is frequent in these patients, particularly in those with uncontrolled hypertension. ${ }^{26} \mathrm{~A}$ high systolic BP seemed to account for most of the risk of progression to ESKD. ${ }^{27}$ Another feature to consider is BP variability. Indeed, short-term systolic BP-variability is common in advanced CKD and analyses suggest that it may be involved in the sharp elevation of cardiovascular risk with worsening renal function. ${ }^{28}$

According to the recent European Hypertension guidelines, the threshold values of $\mathrm{BP}$ for the treatment of hypertension in CKD are $>140 / 90 \mathrm{mmHg}$ and the recommended target is $130-140 \mathrm{mmHg}$ systolic and 70-80 diastolic BP. ${ }^{11}$ Guidelines coming from the United States are stricter with a proposed target $\mathrm{BP}$ at $<130 / 80 \mathrm{mmHg}$ irrespective of the degree of albuminuria. ${ }^{29}$ In 2013, the Kidney Disease Improving Global Outcomes (KDIGO) consensus conference recommended that BP be $<140 / 90$ 
$\mathrm{mmHg}$ in all CKD patients without proteinuria and $\leq 130$ / $80 \mathrm{mmHg}$ in patients with $\mathrm{CKD}$ and proteinuria. ${ }^{30}$ However, KDIGO is now reconsidering these values, as new clinical trials have become available. ${ }^{31}$ So far, the KDIGO group did not publish any new official recommendations regarding target BPs.

Interestingly, there are no specific recommendations for BP targets in patients with advanced CKD and the most recent conclusions of KDIGO emphasized the need to obtain more data on the optimal management of hypertension in CKD stage 3a to stage 5 not on dialysis. ${ }^{31}$ In fact, whereas the benefits of a strict control of BP on cardiovascular outcomes is well recognized, the potential benefits of a well-controlled BP on CKD progression in advanced cases are still discussed. The main concerns are that an intensive lowering of BP in severe CKD might lead to more frequent hypotensive episodes and might eventually worsen kidney function. These concerns are particularly relevant in elderly and in CKD patients with comorbidities such as stroke or coronary heart disease. Table 1 summarizes the target BP recommended by various actual guidelines.

The wiser approach appears to be the individualization of BP targets (but below 140/90 $\mathrm{mmHg}$ ) taking into account age, gender, ethnicity, comorbidities, the patient's acceptation and tolerance of treatments and other ongoing pharmacological therapies. Taken together, the diagnosis and management of hypertension in advanced CKD should take into account the following points:

1. Elevated nighttime BP is common and represents an important BP component of the cardiovascular and renal risk.

2. Ambulatory BP monitoring should be used more frequently to ascertain BP control around the clock. Use only validated devices.

3. Blood pressure should be lowered at least $<140 / 90$ $\mathrm{mmHg}$ in all patients and eventually lower $(<130 / 80$ $\mathrm{mmHg}$ ) in young and/or proteinuric patients.

4. BP targets should however be individualized according to the patient's characteristics, comorbidities and concomitant treatments.

\section{Non-Pharmacological Treatment of Hypertension in Severe CKD}

All hypertension guidelines recommend lifestyle changes as the initial step of the management of hypertension. Of
Table I Target Blood Pressures in the General Population and CKD and Diabetes According to Various Guidelines

\begin{tabular}{|c|c|c|c|}
\hline Society & $\begin{array}{l}\text { General } \\
\text { Population }\end{array}$ & CKD & Diabetes \\
\hline ESC/ESH $2018^{11}$ & $\begin{array}{l}<65 y: \\
<130-120 \\
\text { systolic } \\
<80-70 \\
\text { diastolic } \\
>65 y: \\
<140-130 \\
\text { systolic } \\
<80-70 \\
\text { diastolic }\end{array}$ & $\begin{array}{l}<140-130 \\
\text { systolic } \\
<80-70 \\
\text { diastolic }\end{array}$ & $\begin{array}{l}<65 y: \\
<130-120 \\
\text { systolic } \\
<80-70 \\
\text { diastolic } \\
>65 y \\
<140-130 \\
\text { systolic } \\
<80-70 \\
\text { diastolic }\end{array}$ \\
\hline ACC/AHA $2017^{29}$ & $\begin{array}{l}<130 \text { systolic } \\
<80 \text { diastolic }\end{array}$ & $\begin{array}{l}<130 \text { systolic } \\
<80 \text { diastolic }\end{array}$ & $\begin{array}{l}<130 \text { systolic } \\
<80 \text { diastolic }\end{array}$ \\
\hline KDIGO $2012^{85}$ & & $\begin{array}{l}\text { Without } \\
\text { albuminuria } \\
<140 \text { systolic } \\
<90 \text { diastolic } \\
\text { With } \\
\text { albuminuria } \\
<130 \text { systolic } \\
<80 \text { diastolic }\end{array}$ & \\
\hline NICE $2019^{86}$ & $\begin{array}{l}<80 y: \\
<140 \text { systolic } \\
<90 \text { diastolic } \\
>80 y: \\
<150 \text { systolic } \\
<90 \text { diastolic }\end{array}$ & $\begin{array}{l}<130 \text { systolic } \\
<80 \text { diastolic }\end{array}$ & $\begin{array}{l}\text { Without } \\
\text { albuminuria } \\
<\mid 40 \text { systolic } \\
<90 \text { diastolic } \\
\text { With } \\
\text { albuminuria } \\
<\mid 30 \text { systolic } \\
<80 \text { diastolic }\end{array}$ \\
\hline $\begin{array}{l}\text { Hypertension } \\
\text { Canada } 2020^{87}\end{array}$ & $\begin{array}{l}\text { Low CV risk } \\
\text { to } \\
\text { to high risk } \\
<140 \text { systolic } \\
<90 \text { diastolic }\end{array}$ & $\begin{array}{l}\text { High risk } \\
\text { (severe } \\
\text { CKD) } \\
<120 \\
\text { systolic }\end{array}$ & $\begin{array}{l}<130 \text { systolic } \\
<80 \text { diastolic }\end{array}$ \\
\hline
\end{tabular}

Note: All values are in $\mathrm{mmHg}$.

Abbreviations: Y, years; CV, cardiovascular; CKD, chronic kidney disease.

course, these lifestyle adaptations should be maintained when drug treatments are introduced. In patients with $\mathrm{CKD}$, limitation of sodium intake to $5-6 \mathrm{~g} \mathrm{NaCl} /$ day is an effective intervention to lower BP and albuminuria through every stage of CKD as confirmed in a Cochrane meta-analysis and a recent review of randomized clinical studies. $^{32,33}$ For example, in the LowSALT CKD study, a double blind, placebo-controlled randomized crossover trial conducted in 20 adult patients with hypertension and CKD stages 3 and 4, BP was significantly lower on the 
low than on the high sodium diet, with a mean difference of $-9.7 \mathrm{mmHg}$ for systolic and $-3.9 \mathrm{mmHg}$ for diastolic $\mathrm{BP}^{34}$ In addition to lowering BP, salt restriction potentiates the antihypertensive effect and reinforce the ability of drugs such as blockers of the renin-angiotensin system or diuretics to lower albuminuria. ${ }^{35}$ How much salt patients with advanced CKD should ingest daily is not well defined and whether a reduction of sodium intake enables to retard the progression of kidney diseases remains controversial, despite several observational studies supporting this hypothesis. ${ }^{36}$ Nevertheless, an accepted recommendation is to obtain a sustained reduction of salt intake to about 6 $\mathrm{g} \mathrm{NaCl}$ per day, which is not an easy objective to achieve.

In patients with hypertension and a preserved GFR $\left(\right.$ GFR $\left.>60 \mathrm{~mL} / \mathrm{min} / 1.73 \mathrm{~m}^{2}\right)$, there is now high-quality evidence demonstrating that increasing the potassium content of the diet lowers BP and reduces the incidence of stroke. ${ }^{37}$ Experimentally, potassium has been shown to counterbalance the hypertensive effects of a high sodium diet. ${ }^{38}$ However, the situation is very different in CKD patients with stages $3 b-4$ who may already have slightly elevated serum potassium levels at baseline. In these patients, the risk of hyperkalaemia is very high, specifically in patients with type 2 diabetes. As hyperkalaemia significantly increases the risk of death, physicians should avoid prescribing potassium supplements or drugs increasing serum potassium (such as non-steroidal anti-inflammatory drugs) in patients with an estimated GFR below $45 \mathrm{~mL} / \mathrm{min} / 1.73 \mathrm{~m}^{2}$.

\section{Hypertension Drug Therapy in Severe CKD}

In advanced CKD, recommended BP targets are rarely reached prescribing a single antihypertensive class. This is the reason why European guidelines propose to start immediately with a single pill combination associating a blocker of the renin-angiotensin system (RAS) and a calcium channel blocker (CCB) or a diuretic in CKD patients. ${ }^{11}$ Then, if BP remains uncontrolled, the therapy should be intensified by combining the three drug classes (RAS blocker $+\mathrm{CCB}+$ diuretic), possibly in a single pill. However, the use of antihypertensive drug classes in patients with a low GFR $\left(<30 \mathrm{~mL} / \mathrm{min} / 1.73 \mathrm{~m}^{2}\right)$ deserves some comments:

\section{Blockers of the Renin-Angiotensin System}

Blockers of the renin-angiotensin system are the mainstays of the management of hypertension in CKD because they enable to lower simultaneously systemic BP and the albumin/creatinine ratio. Hence, RAS blockers may contribute to reduce both the cardiovascular and the renal risk of CKD patients. ${ }^{39-41}$ RAS blockers are recommended as first-line therapy by most international hypertension, heart failure, diabetes and kidney diseases guidelines. ${ }^{11,42,43}$ ACC/AHA guidelines 2017 recommend that hypertensive adults with CKD (stages 3 or higher) and albuminuria receive an angiotensin converting enzyme inhibitor (ACEi), or an angiotensin receptor blocker (ARB) in case of ACE intolerance, to slow kidney disease progression. ${ }^{29}$ Yet, there are two issues with the use of RAS blockers in advanced CKD. The first is the risk of hyperkalaemia, which is known to increase the occurrence of cardiac events and sudden deaths. In CKD stages 4 and 5 , the incidence of hyperkalaemia defined as a plasma $\mathrm{K}>$ $5.5 \mathrm{mmol} / \mathrm{L}$ can reach $30 \%$. The second is the acute, reversible, decline in GFR at initiation of therapy, generally in the order of $10-20 \%$ depending on the baseline level of GFR. This decline in GFR can be a major concern in patients with advanced CKD and it is today a frequent cause of withdrawal of RAS blockers in order to gain some kidney function and delay the need of renal replacement therapy. Recent analyses have suggested that any increase in serum creatinine induced by ACEIs or ARBs is associated with a higher risk of $\mathrm{CV}$ events even when the increase is modest $(<30 \%) .{ }^{44}$ Moreover, the evidence that ACEI or ARBs still provide an effective cardiovascular and renal protection in advanced CKD is still weak. Thus, the issue arose of knowing whether RAS blockers should be maintained or stopped in advanced CKD. ${ }^{45,46}$ Today, there are no clear answers to this question and studies are ongoing assessing the benefits and risks of maintaining or stopping RAS blockers in advanced CKD. In one survey, the use of suboptimal doses of RAS inhibitors or withdrawing them in CKD stages 3 and 4, was associated with a two-fold increase in mortality when compared to patients maintained on maximum doses irrespective of comorbidity status. ${ }^{47}$ This would rather support the safety of RAS blockers in advanced CKD and favour the maintenance of RAS blockers when GFR is low. In fact, ACEIs and ARBs should be discontinued only when serious clinical problems arise, such as a substantial GFR decline, severe hyperkalaemia that cannot be readily controlled otherwise, persistent symptomatic hypotension, severe acidosis in the setting of very low GFR, and, potentially, in the very elderly. Today, the availability of potassium binders that can be prescribed chronically, such as patiromer, can help solving the issue 
of hyperkalaemia and should prevent from withdrawing RAS blockers. ${ }^{48}$

\section{Diuretics}

Regarding the use of diuretics in patients with advanced CKD $\left(\mathrm{GFR}<30 \mathrm{~mL} / \mathrm{min} / 1.73 \mathrm{~m}^{2}\right)$, the general concept is that thiazide and thiazide-like diuretics are quasi ineffective and most guidelines recommend the use of short (furosemide) or long-acting (torasemide) loop diuretics. However, this dogma has been challenged as an increasing number of small studies have demonstrated that thiazide diuretics can lower BP even in advanced CKD. ${ }^{49}$ In one of them, long-acting furosemide $(60 \mathrm{mg})$ and hydrochlorothiazide $(25 \mathrm{mg}$ ) were compared. Initially, the two diuretics were given alone for 3 months and then both diuretics were given simultaneously for another 3 months period in 23 patients with hypertension and stages 4 or 5 CKD. ${ }^{50}$ Hydrochlorothiazide was as effective as furosemide in reducing BP and combining the thiazide with the loop diuretic had a synergistic effect. In another randomized trial, amiloride/hydrochlorothiazide (5 mg/50 mg daily) was compared with dietary sodium restriction $(60 \mathrm{mmol}$ per day) in patients with hypertension and CKD stages 3 and 4. The diuretic combination produced a greater decrease in BP than sodium restriction. ${ }^{51}$ Thus, although loop diuretics remain the preferred diuretics in advanced $\mathrm{CKD}$ to control volemia and reduce BP as recommended in guidelines, one may now consider combining them with thiazides. This might be particularly effective in patients with CKD and difficult to control hypertension. Of note, when using thiazides as well as loop diuretics in advanced CKD, higher doses must be prescribed to obtain the desired therapeutic efficacy. Today, studies evaluating the efficacy of chlorthalidone in CKD stage 4 are ongoing. The use of aldosterone antagonists will be discussed below.

\section{Calcium Channel Blockers}

Dihydropyridine (DHP) calcium channel blockers (CCB) are potent vasodilators, which efficaciously lower BP in hypertensive patients with or without CKD. However, their ability to protect kidney function has long be questioned. $^{52}$ Indeed, the classical first- and secondgeneration DHP calcium antagonists, such as nifedipine or amlodipine, increased rather than decreased intraglomerular pressure and hence possibly increased GFR but also proteinuria unless they induced a marked reduction in BP. In addition, in large CKD clinical trials, where they usually served as control group, their impact on kidney progression was repeatedly inferior to that of RAS blockers, despite a comparable reduction in BP. $^{53,54}$ In contrast, DHP calcium antagonists of the third generation such as lercanidipine, have a different effect on kidney function as they lower proteinuria. ${ }^{53}$ At last, the most prevalent side effect of calcium antagonists is the development of peripheral edema. The incidence of edema with CCB is relatively high in patients with advanced $\mathrm{CKD}$ as these patients are already prone to retain sodium and water because of the reduced kidney function. ${ }^{55}$ Noteworthy, diltiazem, a non-DHP calcium antagonist, lowers proteinuria and BP in patients with CKD. $^{52}$ However, diltiazem is a weaker vasodilator than DHP calcium antagonists are and in advanced CKD, physicians may consider the numerous drug interactions (more than 600 interactions described) reported with diltiazem.

Today, there is still a lack of specific trials demonstrating the benefits of calcium antagonist in patients with CKD beyond their impact on BP. Nonetheless, according to hypertension guidelines, $\mathrm{CCB}$ have an important place in the management of hypertension in CKD. This is due mainly to the results of the ACCOMPLISH (Avoiding Cardiovascular Events Through Combination Therapy in Patients Living with Systolic Hypertension) trial conducted in patients with hypertension and a high cardiovascular risk. In this trial, despite a comparable effect on BP, the benazepril-amlodipine combination was surprisingly superior to the benazepril-hydrochlorothiazide combination not only in reducing cardiovascular events ${ }^{56}$ but also in preventing the progression of kidney diseases. ${ }^{55}$ Clinically, one of the limitation in CKD patients was the tolerability profile. Indeed the most frequent adverse event in patients with CKD was peripheral oedema (33.7\% in the benazepril plus amlodipine group and $16.0 \%$ in the benazepril plus hydrochlorothiazide group). ${ }^{55}$

As discussed above, the combination of a DHP calcium antagonist and a RAS blocker is now recommended as first-line therapy for the management of hypertension including in CKD but in advanced CKD most patients will need the triple association of a RAS blocker, a CCB and a diuretic. Calcium antagonists are particularly useful to lower BP in CKD patients of African ancestry alone or in association with diuretics. ${ }^{57}$ Indeed, in a study published in 2019, amlodipine plus hydrochlorothiazide was as effective as amlodipine plus perindopril and more 
effective than perindopril plus hydrochlorothiazide at lowering BP in black patients in sub-Saharan Africa. ${ }^{58}$

\section{Beta-Blockers}

In many recent hypertension guidelines, beta-blockers have been relegated to the 4th or even 5th line of therapy, unless there is a cardiac indication such as coronary heart disease or heart failure. Yet, the prescription of betablockers remains high in the general population as well as in patients with CKD even in the absence of cardiac comorbidity. This may in part be justified by the fact that the activity of the sympathetic nervous system is increased in all CKD stages and particularly when GFR is $<30 \mathrm{~mL} /$ $\min / 1.73 \mathrm{~m}^{2.59,60}$ Therefore, although they are not proposed as first-line therapy, beta-blockers are still useful when BP is difficult to control and other recommended drug classes such as mineralocorticoid antagonists, for example, cannot be prescribed.

\section{Mineralocorticoid Antagonists}

In addition to increasing sodium reabsorption and potassium excretion in the late distal tubule and collecting duct, aldosterone is implicated in renal inflammatory and fibrotic processes. ${ }^{61}$ Thus, in the cardiovascular system, aldosterone has specific hypertrophic and fibrotic effects and can alter endothelial function. In the kidney, aldosterone may induce podocyte injury and mesangial cell proliferation. In line with experimental findings, several clinical studies have demonstrated that aldosterone antagonists such as aldactone or eplerenone, not only lower BP in hypertension but also lower proteinuria. In addition, they may retard CKD progression in diabetic or non-diabetic nephropathies on top of a RAS blocker. ${ }^{62,63}$ Moreover, in resistant hypertension, Williams et al have demonstrated the efficacy of aldactone as 4th line therapy after a RAS blocker, a calcium antagonist and a diuretic. ${ }^{64}$

With these data in hand, one would be tempted to prescribe mineralocorticoid antagonists in advanced $\mathrm{CKD}$, often characterized by a difficult to control BP. In this context, however, the main concern is the occurrence of severe hyperkalaemia taking into account that most of these patients are also receiving a RAS blocker. Wisely, the high risk of hyperkalaemia has been the main limiting factor for a widespread use of aldosterone antagonists in advanced CKD. Aldosterone antagonists might be used in patients with diuretic-induced hypokalaemia or CKD and heart failure but a careful monitoring of serum potassium is mandatory as hyperkalaemia can occur any time during the follow-up of these patients. ${ }^{47}$

Very recently, finerenone, a new nonsteroidal, selective mineralocorticoid receptor antagonist has been reported to lower significantly the risk of CKD progression and cardiovascular events when compared to placebo in patients with CKD stages 3 and 4 and type 2 diabetes. ${ }^{65}$ These cardiovascular and renal benefits were obtained with a very modest effect on systemic BP. Indeed, finerenone decreased mean systolic BP from baseline to month 1 and to month 12 by only -3.0 and $-2.1 \mathrm{mmHg}$, respectively. As expected, the incidence of hyperkalaemia-related discontinuation of the trial regimen was slightly higher with finerenone than with placebo $(2.3 \%$ and $0.9 \%$, respectively) but it remained relatively low. Thus, finerenone will probably be useful to reduce the cardiovascular and renal complications of type 2 diabetes, but not necessarily to ameliorate the BP control of patients with diabetic nephropathy and an uncontrolled BP.

\section{Sympatholytic Agents}

The place of sympatholytic agents in the management of patients with hypertension and advanced CKD is poorly defined as no large randomized controlled trial has demonstrated that this class of antihypertensive agents is able to reduce cardiovascular events or to slow the progression of kidney diseases. Yet there are some indications suggesting that some agents of this drug class may be helpful to complete the treatment of CKD patients with uncontrolled BP. Thus, moxonidine $0.3 \mathrm{mg} / \mathrm{d}$ was found to be as effective as $20 \mathrm{mg}$ nitrendipine in lowering BP on top of a RAS blocker in 177 patients with advanced $\mathrm{CKD}{ }^{66}$ In this study, the increase in serum creatinine was significantly greater with nitrendipine than with moxonidine. Some authors have proposed to revise the place of low doses reserpine in the management of uncontrolled hypertension. ${ }^{67}$ In a small group of patients with refractory hypertension, defined as uncontrolled BP despite $>5$ antihypertensive drugs including a mineralocorticoid antagonist, reserpine reduced mean systolic and diastolic automated office BP by $29.3 \pm 22.2$ and $22.0 \pm 15.8 \mathrm{~mm}$ $\mathrm{Hg}$, respectively. ${ }^{68}$ These results need to be confirmed in a larger number of patients but they suggest that reserpine at low dose, thereby reducing side effects, might be effective in refractory hypertension. Centrally acting drugs such as clonidine or methyldopa are relatively safe in patients with CKD. They may be used in some patients with 
resistant hypertension although there are no specific data in advanced CKD. In patients with resistant hypertension and normal renal function, clonidine was found to be as effective as spironolactone to lower BP. ${ }^{69}$

\section{New Therapies to Lower BP in Hypertension}

In the last 5 years, several new therapeutic options have become available to improve the management of CKD patients reducing their tendency to develop cardiovascular events and to progress towards ESKD. These new therapies concerned essentially patients with type 2 diabetes and a diabetic nephropathy with the development of inhibitors of sodium-glucose cotransporter 2 (SGLT2) or glucagon-like peptide-1 receptor agonists (GLP-1-RA). In patients with type 2 diabetes and kidney disease, both SGLT2-inhibitors and GLP-1-RA demonstrated significant beneficial effects on cardiovascular, mortality, and kidney outcomes. ${ }^{70,71}$ In patients with type 2 diabetes and stages 3b-4 CKD, dapagliflozin did not decrease HbAlc but decreased albuminuria, BP and body weight to a clinically meaningful extent. ${ }^{72}$ In large randomized clinical trials, the marked cardiovascular and renal benefits of SGLT2 inhibitors and GLP-1-RA were obtained with relatively modest decreases in BP suggesting other mechanisms of cardiac and renal protection. Nonetheless, SGLT2 inhibitors have been reported to lower BP effectively even on top of RAS blockers or diuretics. ${ }^{73}$

Whether SGLT2 inhibitors provide the same clinical benefits in patients with diabetic and non-diabetic nephropathies was the main purpose of the DAPA-CKD trial. ${ }^{74}$ DAPA-CKD enrolled 4304 CKD patients with an estimated GFR of $25-75 \mathrm{~mL} / \mathrm{min} / 1.73 \mathrm{~m}^{2}$ and albuminuria of 200-5000 mg/g. ${ }^{75}$ Two-thirds of patients had type 2 diabetes and the median follow-up was 2.4 years. The mean baseline eGFR was $43 \mathrm{~mL} / \mathrm{min} / 1.73 \mathrm{~m}^{2}$ and $14.5 \%$ of patients had a GFR $<30 \mathrm{~mL} / \mathrm{min} / 1.73 \mathrm{~m}^{2}$. The trial was stopped early for overwhelming efficacy. Dapagliflozin reduced significantly the risk of the primary combined endpoint of $>50 \%$ eGFR decline, onset of ESKD or kidney or CV death with a hazard ratio of $0.61 \quad(95 \%$ CI $0.51-0.72){ }^{76}$ The renal benefits were comparable in patients with diabetic and non-diabetic kidney diseases. The impact on cardiac events and mortality were also significant. In heart failure, patients on empagliflozin were also found to be at lower risk of cardiovascular death and hospitalization for heart failure or kidney outcomes than those on placebo, regardless of the presence or absence of diabetes. ${ }^{77}$

The second new therapeutic approach that has been developed to improve the control of BP in hypertension, including in $\mathrm{CKD}$, is renal denervation. Initially, the efficacy of renal denervation was explored essentially in patients with resistant hypertension. In this context, effective renal denervation was found to be safe and to produce meaningful reductions in $\mathrm{BP}$ as assess by office or ambulatory $\mathrm{BP}^{78}$ A more recent study has demonstrated that renal denervation is also effective in untreated patients with essential hypertension. ${ }^{79}$ As activation of the sympathetic nervous system is an important determinant of the cardiovascular and renal risk of patients with CKD, it was reasonable to investigate the potential benefits and risks of renal denervation in CKD. Experimental data in CKD models suggested that renal denervation was indeed effective to control hypertension. ${ }^{80}$ Consequently, the procedure was also tested in patients with moderate to severe CKD and difficult to control BP. Hering et al reported a marked and significant decrease in office and ambulatory BP in 15 patients with resistant hypertension and stages 3-4 CKD (mean GFR, $31 \mathrm{~mL} / \mathrm{min} / 1.73 \mathrm{~m}^{2}$ ) with no deleterious impact on renal function. ${ }^{81}$ Post-hoc analyses of the SIMPLICITY program have also confirm the long-term renal safety of renal denervation in resistant hypertension. Thus, renal denervation represents an additional therapeutic option to control hypertension in advanced CKD but more large randomized controlled trials in hypertensive patients with CKD are needed before recommending a wider use of renal denervation in this population. ${ }^{82}$ In severe CKD, the indication for renal denervation should be evaluated on an individual basis balancing the potential benefits and risks of aggravating renal function. The discussion should preferably involve cardiologists (or radiologists) and nephrologists and treating physicians in an interdisciplinary approach.

\section{Conclusions}

The control of blood pressure in patients with CKD and hypertension is a major task for physicians as a normalization of BP contributes to reduce their cardiovascular and renal risk. However, in advanced CKD, the management of hypertension becomes more delicate for several reasons. Firstly, there are no specific recommendations on how hypertension should be treated in that specific context, because prospective randomized controlled trials are lacking. Secondly, the pharmacology of antihypertensive drugs and the tolerability profile change in advanced CKD and the 


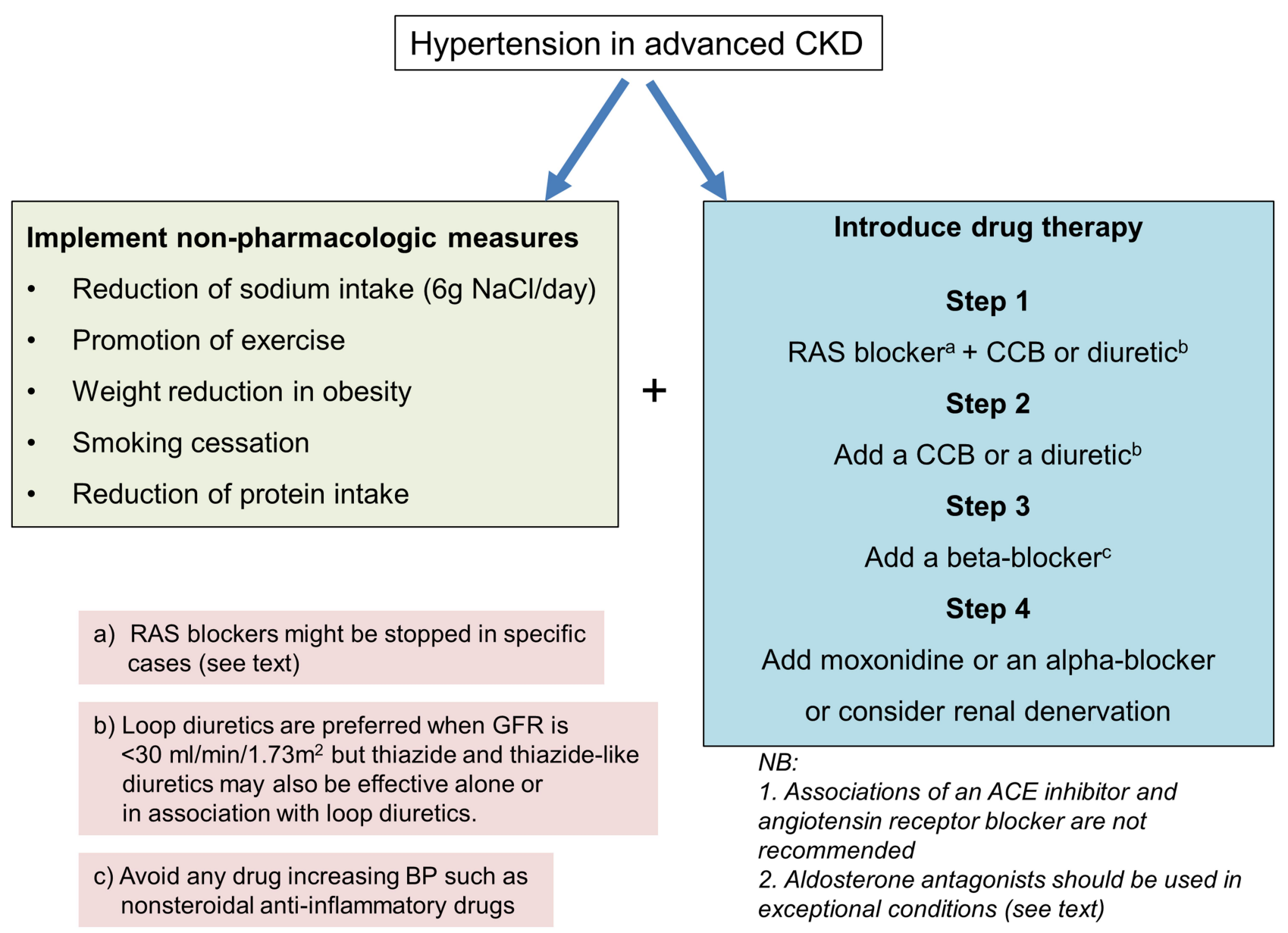

Figure I Schematic representation of a possible strategy to manage hypertension in severe CKD.

incidence of relevant drug-induced side effects (eg peripheral edema, hyperkalemia, worsening of GFR) increases. Thirdly, the cardiovascular and renal benefits of maintaining some drug classes such as RAS blockers are often called into question. Fourthly, patients with CKD belong to the group of subjects with one of the highest burdens of daily pill intake with up to $>20$ pills per day depending on the severity of their disease. ${ }^{83}$ Therefore, poor medication adherence is a real issue in advanced CKD, which can lead to uncontrolled hypertension and a more rapid decline in kidney function. ${ }^{84}$ Despite these limitations, physicians must control BP following a pragmatic approach (as illustrated in Figure 1) taking into account the complexity of the clinical situation, which is accentuated by comorbidities, other CKD complications (anemia, acidosis) and the high pill burden. While waiting for additional supporting evidence from trials, individualization of the management of hypertension in severe CKD appears to be the most reasonable and effective approach taking also into account the patient's preference of care and acceptance of treatments.

\section{Acknowledgment}

The Hypertension Research Foundation in St-Légier, Switzerland has supported the publication of this review.

\section{Disclosure}

The authors of this review have no conflict of interest to declare.

\section{References}

1. Levey AS, de Jong PE, Coresh J, et al. The definition, classification, and prognosis of chronic kidney disease: a KDIGO controversies conference report. Kidney Int. 2011;80(1):17-28. doi:10.1038/ki. 2010.483

2. Levin A, Stevens PE. Summary of KDIGO 2012 CKD Guideline: behind the scenes, need for guidance, and a framework for moving forward. Kidney Int. 2014;85(1):49-61. doi:10.1038/ki.2013.444

3. Bikbov B, Purcell CA, Levey AS; Collaboration GBDCKD. Global, regional, and national burden of chronic kidney disease, 1990-2017: a systematic analysis for the Global Burden of Disease Study 2017. Lancet. 2020;395 (10225):709-733. doi:10.1016/S0140-6736(20)30045-3

4. Hill NR, Fatoba ST, Oke JL, et al. Global prevalence of chronic kidney disease - a systematic review and meta-analysis. PLoS One. 2016;11 (7):e0158765. doi:10.1371/journal.pone.0158765 
5. Gansevoort RT, Correa-Rotter R, Hemmelgarn BR, et al. Chronic kidney disease and cardiovascular risk: epidemiology, mechanisms, and prevention. Lancet. 2013;382(9889):339-352. doi:10.1016/ S0140-6736(13)60595-4

6. Bruck K, Stel VS, Gambaro G, et al. CKD prevalence varies across the european general population. J Am Soc Nephrol. 2016;27 (7):2135-2147. doi:10.1681/ASN.2015050542

7. Report URDSAD. Chapter 1: CKD in the GEneral Population; 2019.

8. Forni Ogna V, Ogna A, Ponte B, et al. Prevalence and determinants of chronic kidney disease in the Swiss population. Swiss Med Wkly. 2016;146:w14313. doi:10.4414/smw.2016.14313

9. Lamine F, Lalubin F, Pitteloud N, Burnier M, Zanchi A. Chronic kidney disease in type 2 diabetic patients followed-up by primary care physicians in Switzerland: prevalence and prescription of antidiabetic drugs. Swiss Med Wkly. 2016;146:w14282. doi:10.4414/ smw.2016.14282

10. Hirst JA, Hill N, O'Callaghan CA, et al. Prevalence of chronic kidney disease in the community using data from OxRen: a UK population-based cohort study. Br J Gen Pract. 2020;70(693):e285e293. doi:10.3399/bjgp20X708245

11. Williams B, Mancia G, Spiering W, et al. 2018 ESC/ESH Guidelines for the management of arterial hypertension: the Task Force for the management of arterial hypertension of the European Society of Cardiology and the European Society of Hypertension: the Task Force for the management of arterial hypertension of the European Society of Cardiology and the European Society of Hypertension. J Hypertens. 2018;36(10):1953-2041. doi:10.1097/HJH.000000000 0001940

12. Go AS, Chertow GM, Fan D, McCulloch CE, Hsu CY. Chronic kidney disease and the risks of death, cardiovascular events, and hospitalization. $N$ Engl J Med. 2004;351(13):1296-1305. doi:10. 1056/NEJMoa041031

13. Keith DS, Nichols GA, Gullion CM, Brown JB, Smith DH. Longitudinal follow-up and outcomes among a population with chronic kidney disease in a large managed care organization. Arch Intern Med. 2004;164(6):659-663. doi:10.1001/archinte. 164.6.659

14. Chronic Kidney Disease PrognosisConsortium. Association of estimated glomerular filtration rate and albuminuria with all-cause and cardiovascular mortality in general population cohorts: a collaborative meta-analysis. Lancet. 2010;375(9731):2073-2081.

15. Stevens LA, Coresh J, Greene T, Levey AS. Assessing kidney function-measured and estimated glomerular filtration rate. $N$ Engl $J$ Med. 2006;354(23):2473-2483. doi:10.1056/NEJMra054415

16. Carmena R, Ascaso JF, Redon J. Chronic kidney disease as a cardiovascular risk factor. J Hypertens. 2020;38(11):2110-2121. doi:10.1097/HJH.0000000000002506

17. Pogue V, Rahman M, Lipkowitz M, et al. Disparate estimates of hypertension control from ambulatory and clinic blood pressure measurements in hypertensive kidney disease. Hypertension. 2009;53 (1):20-27. doi:10.1161/HYPERTENSIONAHA.108.115154

18. Agarwal R, Pappas MK, Sinha AD. Masked uncontrolled hypertension in CKD. J Am Soc Nephrol. 2016;27(3):924-932. doi:10.1681/ ASN.2015030243

19. Drawz PE, Alper AB, Anderson AH, et al. Masked hypertension and elevated nighttime blood pressure in CKD: prevalence and association with target organ damage. Clin J Am Soc Nephrol. 2016;11 (4):642-652. doi:10.2215/CJN.08530815

20. Georgianos PI, Agarwal R. Resistant hypertension in chronic kidney disease (CKD): prevalence, treatment particularities, and research agenda. Curr Hypertens Rep. 2020;22(10):84. doi:10.1007/s11906020-01081-x

21. Lin CH, Lurie RC, Lyons OD. Sleep apnea and chronic kidney disease: a state-of-the-art review. Chest. 2020;157(3):673-685. doi:10.1016/j.chest.2019.09.004
22. Ogna A, Forni Ogna V, Haba Rubio J, et al. Sleep characteristics in early stages of chronic kidney disease in the HypnoLaus Cohort. Sleep. 2016;39(4):945-953. doi:10.5665/sleep.5660

23. Burnier M, Coltamai L, Maillard M, Bochud M. Renal sodium handling and nighttime blood pressure. Semin Nephrol. 2007;27 (5):565-571. doi:10.1016/j.semnephrol.2007.07.007

24. Fukuda M, Munemura M, Usami T, et al. Nocturnal blood pressure is elevated with natriuresis and proteinuria as renal function deteriorates in nephropathy. Kidney Int. 2004;65(2):621-625. doi:10.1111/j.15231755.2004.00419.x

25. Cohen DL, Huan Y, Townsend RR. Ambulatory blood pressure in chronic kidney disease. Curr Hypertens Rep. 2013;15(3):160-166. doi:10.1007/s11906-013-0339-2

26. Agarwal R, Andersen MJ. Correlates of systolic hypertension in patients with chronic kidney disease. Hypertension. 2005;46(3):51 4-520. doi:10.1161/01.HYP.0000178102.85718.66

27. Peralta CA, Norris $\mathrm{KC}$, Li S, et al. Blood pressure components and end-stage renal disease in persons with chronic kidney disease: the Kidney Early Evaluation Program (KEEP). Arch Intern Med. 2012;172(1):41-47. doi:10.1001/archinternmed.2011.619

28. Sarafidis PA, Ruilope LM, Loutradis C, et al. Blood pressure variability increases with advancing chronic kidney disease stage: a crosssectional analysis of 16546 hypertensive patients. J Hypertens. 2018;36(5):1076-1085. doi:10.1097/HJH.0000000000001670

29. Whelton PK, Carey RM. The 2017 clinical practice guideline for high blood pressure. JAMA. 2017;318(21):2073-2074. doi:10.1001/jama. 2017.18209

30. Wheeler DC, Becker GJ. Summary of KDIGO guideline. What do we really know about management of blood pressure in patients with chronic kidney disease? Kidney Int. 2013;83(3):377-383. doi:10.1038/ki.20 12.425

31. Cheung AK, Chang TI, Cushman WC, et al. Blood pressure in chronic kidney disease: conclusions from a Kidney Disease: Improving Global Outcomes (KDIGO) Controversies Conference. Kidney Int. 2019;95(5):1027-1036. doi:10.1016/j.kint.2018.12.025

32. Garofalo C, Borrelli S, Provenzano M, et al. Dietary salt restriction in chronic kidney disease: a meta-analysis of randomized clinical trials. Nutrients. 2018;10(6):732. doi:10.3390/nu10060732

33. McMahon EJ, Campbell KL, Bauer JD, Mudge DW. Altered dietary salt intake for people with chronic kidney disease. Cochrane Database Syst Rev. 2015;2:Cd010070. doi:10.1002/14651858.CD010070.pub2

34. McMahon EJ, Bauer JD, Hawley CM, et al. A randomized trial of dietary sodium restriction in CKD. J Am Soc Nephrol. 2013;24 (12):2096-2103. doi:10.1681/ASN.2013030285

35. Lambers Heerspink HJ, Holtkamp FA, Parving HH, et al. Moderation of dietary sodium potentiates the renal and cardiovascular protective effects of angiotensin receptor blockers. Kidney Int. 2012;82 (3):330-337. doi:10.1038/ki.2012.74

36. Burnier M. Sodium intake and progression of chronic kidney disease-has time finally come to do the impossible: a prospective randomized controlled trial? Nephrol Dial Transplant. 2020. doi:10.1093/ndt/gfaa120

37. Aburto NJ, Hanson S, Gutierrez H, Hooper L, Elliott P, Cappuccio FP. Effect of increased potassium intake on cardiovascular risk factors and disease: systematic review and meta-analyses. BMJ. 2013;346:f1378. doi:10.1136/bmj.f1378

38. Burnier M. Should we eat more potassium to better control blood pressure in hypertension? Nephrol Dial Transplant. 2019;34 (2):184-193. doi:10.1093/ndt/gfx340

39. Brenner BM, Cooper ME, de Zeeuw D, et al. Effects of losartan on renal and cardiovascular outcomes in patients with type 2 diabetes and nephropathy. N Engl J Med. 2001;345(12):861-869. doi:10.1056/ NEJMoa011161

40. Hou FF, Zhang X, Zhang GH, et al. Efficacy and safety of benazepril for advanced chronic renal insufficiency. $N$ Engl J Med. 2006;354 (2):131-140. doi:10.1056/NEJMoa053107 
41. Lewis EJ, Hunsicker LG, Clarke WR, et al. Renoprotective effect of the angiotensin-receptor antagonist irbesartan in patients with nephropathy due to type 2 diabetes. $N$ Engl J Med. 2001;345 (12):851-860. doi:10.1056/NEJMoa011303

42. Ponikowski P, Voors AA, Anker SD, et al. 2016 ESC Guidelines for the diagnosis and treatment of acute and chronic heart failure: the Task Force for the diagnosis and treatment of acute and chronic heart failure of the European Society of Cardiology (ESC) developed with the special contribution of the Heart Failure Association (HFA) of the ESC. Eur Heart J. 2016;37(27):2129-2200. doi:10.1093/eurheartj/ ehw128

43. Taler SJ, Agarwal R, Bakris GL, et al. KDOQI US commentary on the 2012 KDIGO clinical practice guideline for management of blood pressure in CKD. Am J Kidney Dis. 2013;62(2):201-213. doi:10. 1053/j.ajkd.2013.03.018

44. Schmidt M, Mansfield KE, Bhaskaran K, et al. Serum creatinine elevation after renin-angiotensin system blockade and long term cardiorenal risks: cohort study. BMJ. 2017;356:j791. doi:10.1136/ bmj.j791

45. Ahmed A, Jorna T, Bhandari S. Should we STOP angiotensin converting enzyme inhibitors/angiotensin receptor blockers in advanced kidney disease? Nephron. 2016;133(3):147-158. doi:10.1159/000447068

46. Burnier M. Renin-angiotensin system blockade in advanced kidney disease: stop or continue? Kidney Med. 2020;2(3):231-234. doi:10.1016/j.xkme.2020.04.002

47. Epstein M, Reaven NL, Funk SE, McGaughey KJ, Oestreicher N, Knispel J. Evaluation of the treatment gap between clinical guidelines and the utilization of renin-angiotensin-aldosterone system inhibitors. Am J Manag Care. 2015;21(11 Suppl):S212-220.

48. Weir MR, Bakris GL, Bushinsky DA, et al. Patiromer in patients with kidney disease and hyperkalemia receiving RAAS inhibitors. $N$ Engl $J$ Med. 2015;372(3):211-221. doi:10.1056/NEJMoa1410853

49. Sinha AD, Agarwal R. Thiazides are useful agents in CKD. J Am Soc Hypertens. 2016;10(4):288-289. doi:10.1016/j.jash.2016.02.006

50. Dussol B, Moussi-Frances J, Morange S, Somma-Delpero C, Mundler O, Berland Y. A pilot study comparing furosemide and hydrochlorothiazide in patients with hypertension and stage 4 or 5 chronic kidney disease. J Clin Hypertens (Greenwich). 2012;14 (1):32-37. doi:10.1111/j.1751-7176.2011.00564.x

51. Bovee DM, Visser WJ, Middel I, et al. A randomized trial of distal diuretics versus dietary sodium restriction for hypertension in chronic kidney disease. J Am Soc Nephrol. 2020;31(3):650-662. doi:10.1681/ ASN.2019090905

52. Wright JT Jr., Bakris G, Greene T, et al. Effect of blood pressure lowering and antihypertensive drug class on progression of hypertensive kidney disease: results from the AASK trial. JAMA. 2002;288 (19):2421-2431. doi:10.1001/jama.288.19.2421

53. Burnier M. Renal protection with calcium antagonists: the role of lercanidipine. Curr Med Res Opin. 2013;29(12):1727-1735. doi:10.1185/03007995.2013.842891

54. Zanchi A, Brunner HR, Waeber B, Burnier M. Renal haemodynamic and protective effects of calcium antagonists in hypertension. J Hypertens. 1995;13(12 Pt 1):1363-1375. doi:10.1097/00004872199512000-00002

55. Bakris GL, Sarafidis PA, Weir MR, et al. Renal outcomes with different fixed-dose combination therapies in patients with hypertension at high risk for cardiovascular events (ACCOMPLISH): a prespecified secondary analysis of a randomised controlled trial. Lancet. 2010;375 (9721):1173-1181. doi:10.1016/S0140-6736(09)62100-0

56. Jamerson K, Weber MA, Bakris GL, et al. Benazepril plus amlodipine or hydrochlorothiazide for hypertension in high-risk patients. $N$ Engl J Med. 2008;359(23):2417-2428. doi:10.1056/NEJMoa0806182

57. Flack JM, Sica DA, Bakris G, et al. Management of high blood pressure in Blacks: an update of the International Society on Hypertension in Blacks consensus statement. Hypertension. 2010;56 (5):780-800. doi:10.1161/HYPERTENSIONAHA.110.152892
58. Ojji DB, Mayosi B, Francis V, et al. Comparison of dual therapies for lowering blood pressure in Black Africans. N Engl J Med. 2019;380 (25):2429-2439. doi:10.1056/NEJMoa1901113

59. Penne EL, Neumann J, Klein IH, Oey PL, Bots ML, Blankestijn PJ. Sympathetic hyperactivity and clinical outcome in chronic kidney disease patients during standard treatment. J Nephrol. 2009;22(2):208-215.

60. Converse RL Jr., Jacobsen TN, Toto RD, et al. Sympathetic overactivity in patients with chronic renal failure. $N$ Engl J Med. 1992;327(27):1912-1918. doi:10.1056/NEJM199212313272704

61. Briet M, Schiffrin EL. Aldosterone: effects on the kidney and cardiovascular system. Nat Rev Nephrol. 2010;6(5):261-273. doi:10.1038/ nrneph. 2010.30

62. Currie G, Taylor AH, Fujita T, et al. Effect of mineralocorticoid receptor antagonists on proteinuria and progression of chronic kidney disease: a systematic review and meta-analysis. BMC Nephrol. 2016;17(1):127.

63. Chung EY, Ruospo M, Natale P, et al. Aldosterone antagonists in addition to renin angiotensin system antagonists for preventing the progression of chronic kidney disease. Cochrane Database Syst Rev. 2020;10:Cd007004. doi:10.1002/14651858.CD007004.pub4

64. Williams B, MacDonald TM, Morant S, et al. Spironolactone versus placebo, bisoprolol, and doxazosin to determine the optimal treatment for drug-resistant hypertension (PATHWAY-2): a randomised, double-blind, crossover trial. Lancet. 2015;386(10008):2059-2068. doi:10.1016/S0140-6736(15)00257-3

65. Bakris GL, Agarwal R, Anker SD, et al. Effect of Finerenone on chronic kidney disease outcomes in type 2 diabetes. $N$ Engl $\mathrm{J} \mathrm{Med}$. 2020;383(23):2219-2229. doi:10.1056/NEJMoa2025845

66. Vonend O, Marsalek P, Russ H, Wulkow R, Oberhauser V, Rump LC. Moxonidine treatment of hypertensive patients with advanced renal failure. J Hypertens. 2003;21(9):1709-1717. doi:10.1097/00004872200309000-00021

67. Barzilay J, Grimm R, Cushman W, Bertoni AG, Basile J. Getting to goal blood pressure: why reserpine deserves a second look. J Clin Hypertens (Greenwich). 2007;9(8):591-594. doi:10.1111/j.1524-61 75.2007.07229.x

68. Siddiqui M, Bhatt H, Judd EK, Oparil S, Calhoun DA. Reserpine substantially lowers blood pressure in patients with refractory hypertension: a Proof-of-Concept Study. Am J Hypertens. 2020;33(8): 741-747. doi:10.1093/ajh/hpaa042

69. Krieger EM, Drager LF, Giorgi DMA, et al. Spironolactone versus clonidine as a fourth-drug therapy for resistant hypertension. Hypertension. 2018;71(4):681-690. doi:10.1161/HYPERTENSIONAHA.117.10662

70. Kristensen SL, Rorth R, Jhund PS, et al. Cardiovascular, mortality, and kidney outcomes with GLP-1 receptor agonists in patients with type 2 diabetes: a systematic review and meta-analysis of cardiovascular outcome trials. Lancet Diabetes Endocrinol. 2019;7(10):7 76-785. doi:10.1016/S2213-8587(19)30249-9

71. Zelniker TA, Wiviott SD, Raz I, et al. SGLT2 inhibitors for primary and secondary prevention of cardiovascular and renal outcomes in type 2 diabetes: a systematic review and meta-analysis of cardiovascular outcome trials. Lancet. 2019;393(10166):31-39. doi:10.1016/S01406736(18)32590-X

72. Dekkers CCJ, Wheeler DC, Sjöström CD, Stefansson BV, Cain V, Heerspink HJL. Effects of the sodium-glucose co-transporter 2 inhibitor dapagliflozin in patients with type 2 diabetes and Stages $3 \mathrm{~b}-4$ chronic kidney disease. Nephrol Dial Transplant. 2018;33 (11):2005-2011. doi:10.1093/ndt/gfx350

73. Mancia G, Cannon CP, Tikkanen I, et al. Impact of empagliflozin on blood pressure in patients with type 2 diabetes mellitus and hypertension by background antihypertensive medication. Hypertension. 2016;68 (6):1355-1364. doi:10.1161/HYPERTENSIONAHA.116.07703

74. Heerspink HJL, Stefansson BV, Chertow GM, et al. Rationale and protocol of the Dapagliflozin And Prevention of Adverse outcomes in Chronic Kidney Disease (DAPA-CKD) randomized controlled trial. Nephrol Dial Transplant. 2020;35(2):274-282. doi:10.1093/ndt/ gfz290 
75. Heerspink HJL, Stefansson BV, Correa-Rotter R, et al. Dapagliflozin in patients with chronic kidney disease. $N$ Engl J Med. 2020;383 (15):1436-1446. doi:10.1056/NEJMoa2024816

76. Fernandez-Fernandez B, Sarafidis P, Kanbay M, et al. SGLT2 inhibitors for non-diabetic kidney disease: drugs to treat CKD that also improve glycaemia. Clin Kidney J. 2020;13(5):728-733. doi:10.1093/ $\mathrm{ckj} / \mathrm{sfaa} 198$

77. Packer M, Anker SD, Butler J, et al. Cardiovascular and renal outcomes with empagliflozin in heart failure. $N$ Engl J Med. 2020;383 (15):1413-1424. doi:10.1056/NEJMoa2022190

78. Stavropoulos K, Patoulias D, Imprialos K, et al. Efficacy and safety of renal denervation for the management of arterial hypertension: A systematic review and meta-analysis of randomized, sham-controlled, catheter-based trials. J Clin Hypertens (Greenwich). 2020;22(4):572-584. doi:10.1111/jch.13827

79. Bohm M, Kario K, Kandzari DE, et al. Efficacy of catheter-based renal denervation in the absence of antihypertensive medications (SPYRAL HTN-OFF MED Pivotal): a multicentre, randomised, sham-controlled trial. Lancet. 2020;395(10234):1444-1451.

80. Singh RR, Denton KM. Renal Denervation. Hypertension. 2018;72 (3):528-536. doi:10.1161/HYPERTENSIONAHA.118.10265

81. Hering D, Mahfoud F, Walton AS, et al. Renal denervation in moderate to severe CKD. J Am Soc Nephrol. 2012;23(7):1250-1257. doi:10.1681/ASN.2011111062
82. Veelken R, Schmieder RE. Renal denervation-implications for chronic kidney disease. Nat Rev Nephrol. 2014;10(6):305-313. doi:10.1038/nrneph.2014.59

83. Burnier M, Pruijm M, Wuerzner G, Santschi V. Drug adherence in chronic kidney diseases and dialysis. Nephrol Dial Transplant. 2015;30(1):39-44. doi:10.1093/ndt/gfu015

84. Schmitt KE, Edie CF, Laflam P, Simbartl LA, Thakar CV. Adherence to antihypertensive agents and blood pressure control in chronic kidney disease. Am J Nephrol. 2010;32(6):541-548. doi:10.1159/ 000321688

85. KDIGO Clinical Practice. Guideline for the management of blood pressure in chronic kidney disease. Kidney Int Supple. 2012;2 (5):372-376.

86. Boffa RJ, Constanti M, Floyd CN, Wierzbicki AS. Hypertension in adults: summary of updated NICE guidance. BMJ. 2019;367:15310. doi:10.1136/bmj.15310

87. Rabi DM, McBrien KA, Sapir-Pichhadze R, et al. Hypertension Canada's 2020 comprehensive guidelines for the prevention, diagnosis, risk assessment, and treatment of hypertension in adults and children. Can J Cardiol. 2020;36(5):596-624. doi:10.1016/j.cjca.20 20.02.086
Vascular Health and Risk Management

\section{Publish your work in this journal}

Vascular Health and Risk Management is an international, peerreviewed journal of therapeutics and risk management, focusing on concise rapid reporting of clinical studies on the processes involved in the maintenance of vascular health; the monitoring, prevention and treatment of vascular disease and its sequelae; and the involvement
Dovepress

of metabolic disorders, particularly diabetes. This journal is indexed on PubMed Central and MedLine. The manuscript management system is completely online and includes a very quick and fair peerreview system, which is all easy to use. Visit http://www.dovepress. com/testimonials.php to read real quotes from published authors. 